\title{
Reliability of Permanent Mandibular Canine Calcification as an Indicator of Skeletal Maturity in Karnataka Population*
}

\author{
${ }^{1} \mathrm{R}$ Divyashree, ${ }^{2} \mathrm{MR}$ Dinesh, ${ }^{3} \mathrm{BC}$ Amarnath \\ ${ }^{1}$ Assistant Professor, Department of Orthodontics and Dentofacial Orthopedics, Sri Venkateshwara NSVK Dental College and \\ Hospital, Bengaluru, Karnataka, India \\ ${ }^{2}$ Professor and Head, Department of Orthodontics and Dentofacial Orthopedics, DA Pandu Memorial RV Dental College and \\ Hospital, Bengaluru, Karnataka, India \\ ${ }^{3}$ Professor, Department of Orthodontics and Dentofacial Orthopedics, DA Pandu Memorial RV Dental College and Hospital \\ Bengaluru, Karnataka, India
}

Correspondence: R Divyashree, 108, Sai Poorna Heights Apartment, 27th Main, Somasundara Palya, 2nd Sector, HSR Layout, Bengaluru-560102, Karnataka, India, Phone: (+91) 9845693638, e-mail: divyashree.r@gmail.com

\begin{abstract}
Aims: The purpose of this study was to assess the reliability of permanent mandibular canine tooth calcification as an indicator of skeletal maturity in Karnataka population by comparing it with the ossification stages of the middle phalanx of the left third finger and also to compare the sexual dimorphism in the timing of these events.

Methods: This study was performed on 100 subjects (50 boys and 50 girls) of South Indian origin aged 10 to 14 years. Radiovisiographs of the middle phalanx of the left third finger and Orthopantomographs were obtained and assessed for the stages of calcification using the methods described by Hagg and Taranger and by Demirjian et al respectively. The correlation between various stages of lower canine calcification and stages of MP3 ossification was assessed for both the sexes using Chi-square test and percentage distributions. Results: The associations were statistically significant only between MP3-F and canine F stages in both sexes ( $88 \%$ for boys, $59 \%$ for girls) and MP3-H and canine $\mathrm{H}$ stages in boys (100\%). Also girls showed an advanced trend in dental maturation.

Conclusion: The mandibular canine calcification stages alone are not as reliable an indicator as MP3 stages for assessing the skeletal maturity in Karnataka population.

Keywords: Pubertal growth spurt, middle phalanx of the third finger (MP3), mandibular canine calcification stages, radiovisiographs.
\end{abstract}

\section{INTRODUCTION}

The determination of skeletal maturity and growth potential of the patient has a considerable influence on diagnosis, treatment goals, treatment planning, retention and the eventual outcome of treatment in orthodontics and dentofacial orthopedics. ${ }^{1}$ Conventionally hand-w rist radiographs or cervical vertebrae on lateral cephal ograms have been used to assess skeletal maturity level.

Dental development, particularly of mandibular canine tooth has also been studied in relation to skeletal maturational development. ${ }^{1-7}$ The availability of intraoral or panoramic radiographs in most orthodontic practices, are the practical reasons for attempting to assess skeletal maturity of the patient using dental calcification, without resorting to hand-w rist radiographs. However, the findings relating the dental maturation to skeletal maturation have been contradictory. ${ }^{8-10}$ Also racial and gender variations have been suggested. ${ }^{3,4,11}$
We attempted to investigate the association of mandibular canine calcification to M P3 ossification stages and its potential to be used as a pubertal growth spurt indicator in Karnataka population. We compared the difference in the timing of these events in boys and girls based on their chronological age to study any sexual dimorphism.

\section{MATERIALS AND METHODS}

The sample included 100 subjects, 50 boys and 50 girls of Karnataka origin, registered as patients in the department of Orthodontics and Dentofacial Orthopedics, DA Pandu Memorial RV Dental College and Hospital, Bangalore, India. The age group of 10 to 14 years was chosen, as the pubertal growth spurt events occuring during this period are of clinical importance. The inclusion criteria were untreated, healthy individuals with no history of trauma to face and hand-wrist regions. All subjects were explained

\footnotetext{
*This paper is from the thesis done by the first author ( $D r R$ Divyashree) for the partial fulfillment of M DS degree in Orthodontics and D entofacial Orthopedics, submitted to the Rajiv Gandhi University of Health Sciences, B engaluru, Karnataka, India (A pril 2008).
} 


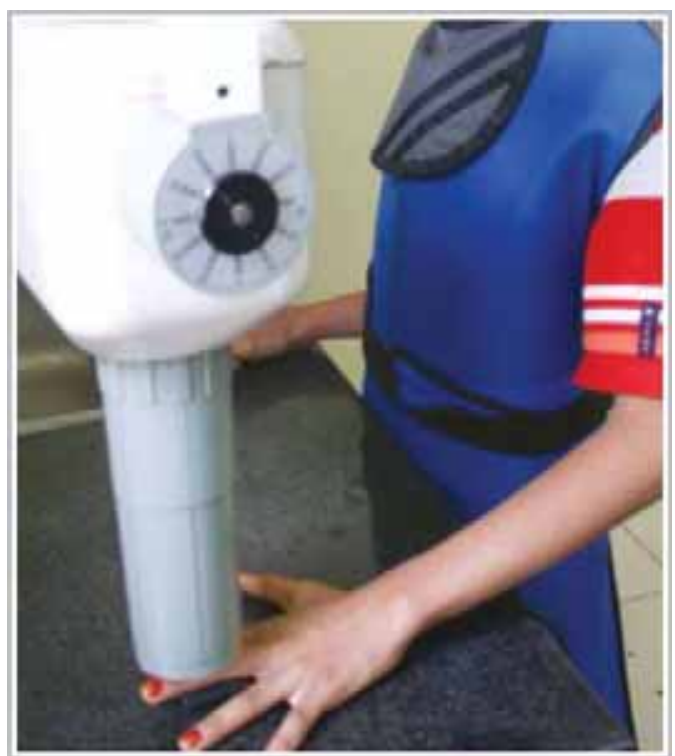

Fig. 1: Subject positioned for RVG-MP3

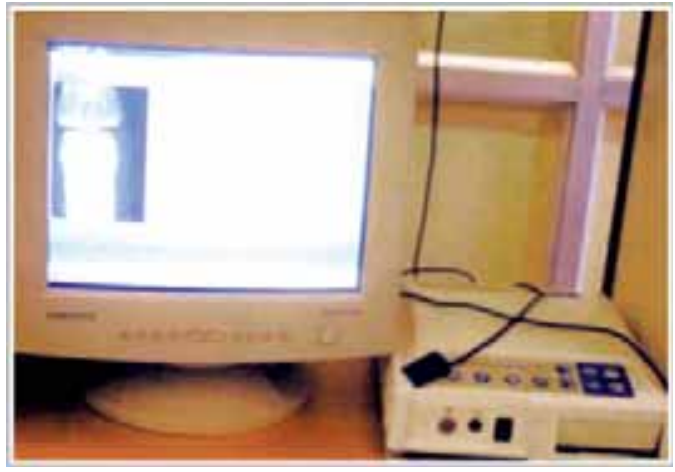

Fig. 2: Digital image of MP3

the need and design of the study and a written consent was obtained. Exact chronological ages in completed years and months were recorded.

Radiovisiographs (Trophy, Radiologie) for the middle phal anx of the third finger (M P3) of left hand of the subjects were made as per the standardized method ${ }^{12}$ (Fig. 1). Digital images were obtained using $V$ ixwinpro software programme (Gendex, Dentsply) (Fig. 2). The digital images of MP3 were randomly coded and assessed for the stages of ossification according to the system described by $\mathrm{H}$ agg and Taranger. ${ }^{13}$

\section{MP3 Ossification Stages: Hagg and Taranger Method ${ }^{13}$}

MP3-F stage: Start of the curve of pubertal growth spurt

Epiphysis is as wide as metaphysis. Radiolucent gap between epiphysis and metaphysis is wide.

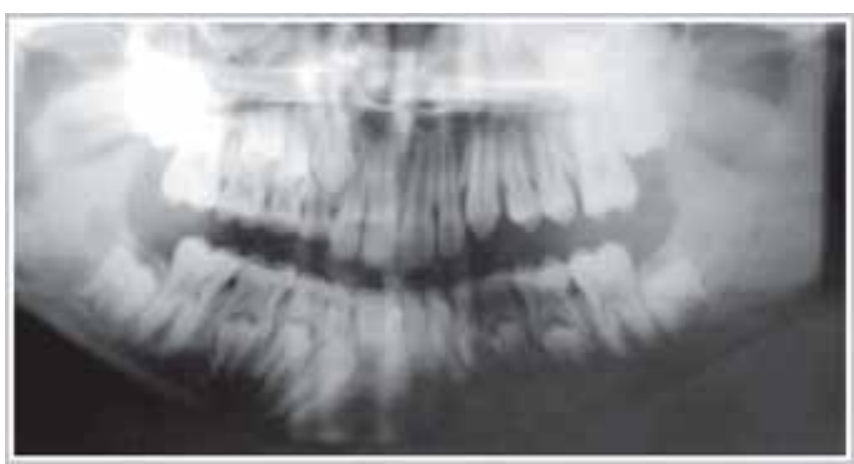

Fig. 3: Coded OPG

MP3-FG stage: A cceleration of the curve of pubertal growth spurt.

Distinct medial and/or lateral border of epiphysis forms line of demarcation at right angle to distal border.

MP3-G stage: M aximum point of pubertal growth spurt

Sides of epiphysis have thickened and cap its metaphysis, forming sharp distal edge on one or both sides. Marked undulations in metaphysis give it "Cupid's bow" appearance.

MP3-H stage: Deceleration of the curve of pubertal growth spurt.

Fusion of epiphysis and metaphysis begins. Radiolucent gap between epiphysis and metaphysic is narrower.

MP3-I stage: End of pubertal growth spurt

Fusion of epiphysis and metaphysis complete

Panoramic radiographs (Gendex Orthoralix 9200) routinely taken for the treatment purpose were obtained, coded and randomized (Fig. 3). M andibular left canine tooth was examined in panoramic radiograph for calcification and rated according to the method described by Demirjian, Goldstein and Tanner. ${ }^{14}$

\section{Dental Calcification Stages: Demirjian, Goldstein and Tanner Method ${ }^{14}$}

Stage F: The walls of the pulp canal form an isosceles triangle. The apex ends in a funnel shape. The root length is equal to or greater than the crown height.

Stage G: The walls of the root canal are now parallel and its apical end is still partially open.

Stage H: The apical end of the root canal is completely closed. The periodontal membrane has a uniform width around the root and the apex.

The correlation between various stages of mandibular canine calcification and M P3 ossification was assessed for 
all subjects using $\mathrm{C}$ hi-square test with the probability value of $p<0.001$. The mean and standard deviation of chronological ages at each MP3 and canine calcification stage were tabulated to study the difference in the timing of both the events between boys and girls.

\section{RESULTS}

The association between various MP3 ossification stages and lower canine calcification stages and their percentage distribution in boys and girls was recorded (T ables 1 and 2, Graphs 1 and 2). At the M P3-F stage for boys, the canine stage $F$ showed a significant association of 88 percent. At M P3-H stage for boys, canine stage $\mathrm{H}$ showed a highly significant association of 100 percent. A the M P3-F stage for girls, the canine stage $F$ showed 59 percent distribution indicating a significant association between M P3-F and canine F stages.

Comparing the mean chronological age in years at different M P3 stages indicated that each stage occurs earlier in girls than boys in a range of 0.1 to 1.5 years (T able 3 ).

The mean chronological age in years at different canine calcification stages was compared between boys and girls
(Table 4). The canine calcification stage $F$ occurred at a mean age of 10.9 years in both the sexes ( 0 year difference), canine calcification stage $G$ was seen at 12.8 years in boys and 12.2 years in girls ( 0.6 year difference); canine calcification stage $\mathrm{H}$ occurred at 13.8 years in boys and 12.8 years in girls (1 year difference).

\section{DISCUSSION}

In this study, we attempted to assess the reliability of permanent mandibular canine calcification as an indicator of skeletal maturity in subjects of Karnataka origin by comparing it with MP3 ossification stages. We found that the mandibular canine stage $F$ showed a significant association with the M P3-F stage indicating the onset of pubertal growth in both boys (88 percent) and girls (59 percent). The canine stage $H$ showed a highly significant association with the M P3-H stage in boys (100 percent) indicative of the period of decelerating growth velocity. This is in contrast to the study by Krailassiri et $\mathrm{al}^{1}$ on Thai individuals in whom canine stage $\mathrm{H}$ coincided with the M P3$G$ stage in majority of the boys indicating peak growth period. In this study the canine stage $G$ did not show

Table 1: Association of MP3 and mandibular canine calcification stages

\begin{tabular}{|c|c|c|c|c|c|c|}
\hline \multirow[t]{2}{*}{ MP3 stages } & \multicolumn{6}{|c|}{ Mandibular canine calcification stages } \\
\hline & Boys & Girls & Boys & Girls & Boys & Girls \\
\hline $\mathrm{F}$ & $30(88 \%)^{*}$ & $7(59 \%)^{*}$ & $0(0 \%)$ & $4(22 \%)$ & $0(0 \%)$ & $0(0 \%)$ \\
\hline$F G$ & $3(9 \%)$ & $3(25 \%)$ & $5(45.5 \%)$ & $3(17 \%)$ & $0(0 \%)$ & $0(0 \%)$ \\
\hline G & $0(0 \%)$ & $1(8 \%)$ & 5 (45.5\%) & $5(28 \%)$ & $0(0 \%)$ & $2(10 \%)$ \\
\hline $\mathrm{H}$ & $1(3 \%)$ & $0(0 \%)$ & $1(9 \%)$ & $6(33 \%)$ & $5(100 \%)^{* *}$ & $9(45 \%)$ \\
\hline I & $0(0 \%)$ & $1(8 \%)$ & $0(0 \%)$ & $0(0 \%)$ & $0(0 \%)$ & $9(45 \%)$ \\
\hline Total subjects & 34 & 12 & 11 & 18 & 5 & 20 \\
\hline
\end{tabular}

( ) percent distribution

**highly significant; *significant association at $p$-value $<0.001$

Table 2: Measurement of association between MP3 stages and canine calcification stages

\begin{tabular}{|lll|}
\hline MP3 stages & Boys & Girls \\
\hline F & 0.76 & 0.66 \\
FG & 0.38 & 0.19 \\
G & 0.56 & 0.23 \\
H & 0.78 & 0.21 \\
I & - & 0.20 \\
\hline
\end{tabular}

Table 3: Age distribution for MP3 stages

\begin{tabular}{|c|c|c|c|c|c|}
\hline \multirow[t]{3}{*}{ MP3 sta } & \multicolumn{5}{|c|}{ Chronological age (years) } \\
\hline & \multicolumn{2}{|c|}{ Boys } & \multicolumn{2}{|c|}{ Girls } & \multirow{2}{*}{$\begin{array}{c}\text { Gender difference } \\
\text { Mean }\end{array}$} \\
\hline & Mean & $S D$ & Mean & $S D$ & \\
\hline $\mathrm{F}$ & 10.9 & 0.8 & 10.8 & 0.7 & 0.1 \\
\hline$F G$ & 12.0 & 1.0 & 11.1 & 0.9 & 0.9 \\
\hline G & 13.4 & 0.6 & 11.9 & 1.5 & 1.5 \\
\hline $\mathrm{H}$ & 13.5 & 0.8 & 12.9 & 0.9 & 0.6 \\
\hline I & - & - & 13.1 & 1.0 & - \\
\hline
\end{tabular}




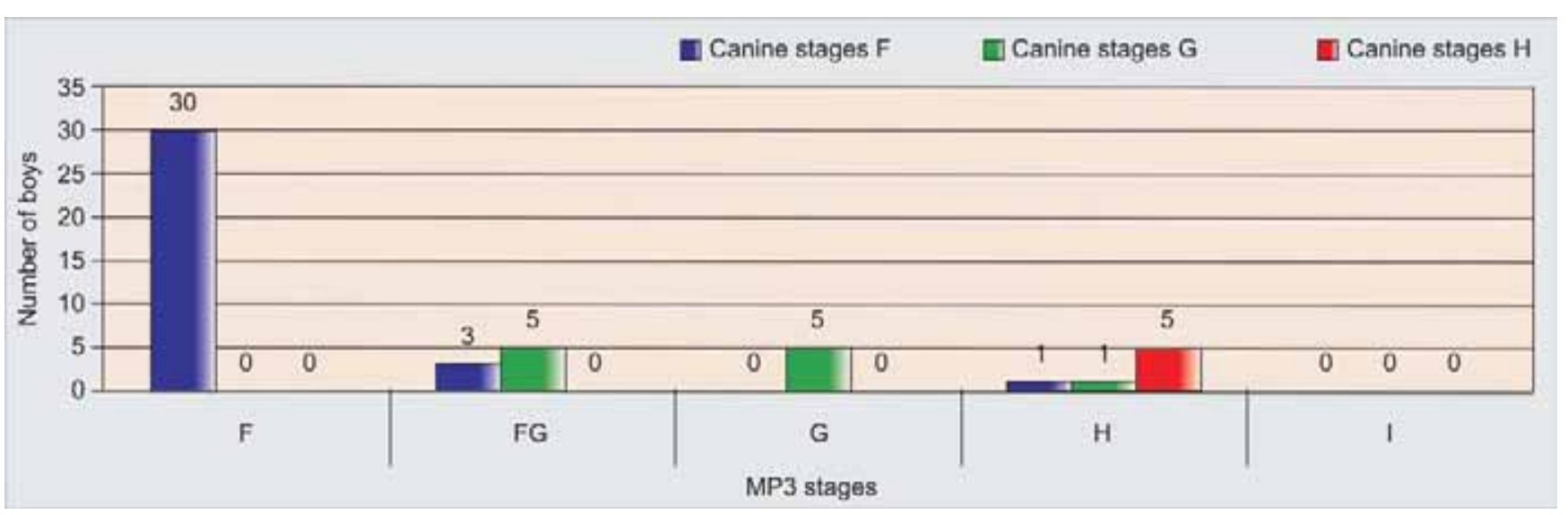

Graph 1: Association of MP3 and mandibular canine calcification stages in boys

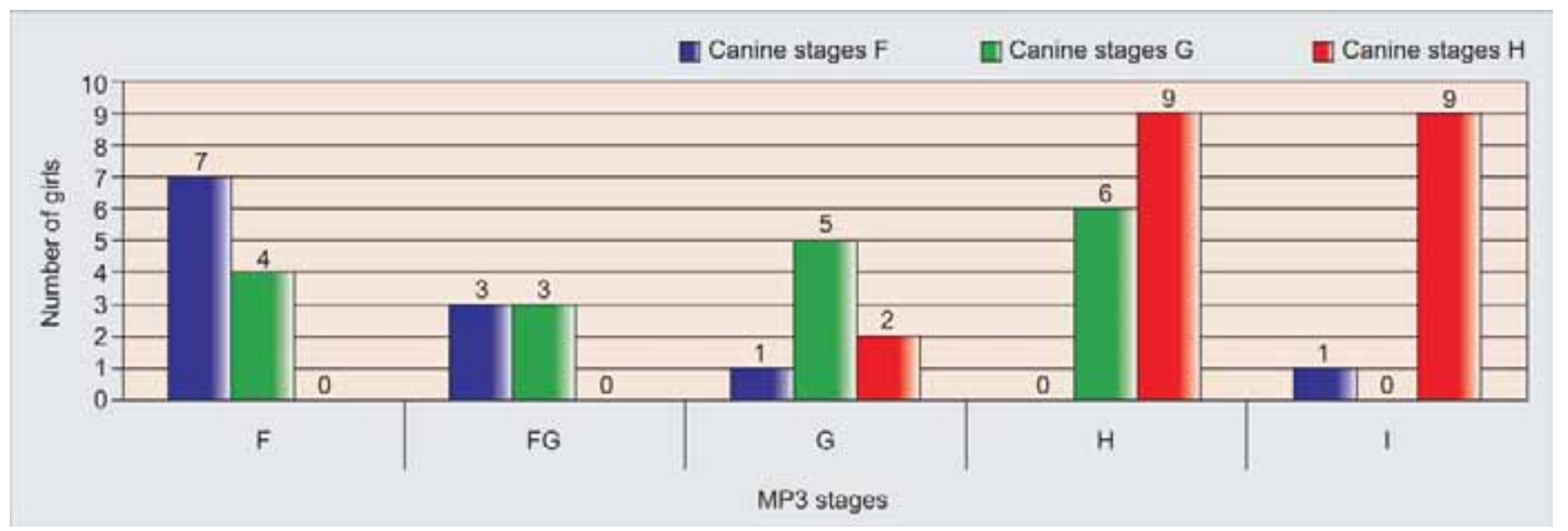

Graph 2: Association of MP3 and mandibular canine calcification stages in girls

Table 4: Age distribution for canine calcification stages

\begin{tabular}{|c|c|c|c|c|c|}
\hline \multicolumn{2}{|c|}{ Canine calcification } & \multicolumn{4}{|c|}{ Chronological age (years) } \\
\hline \multirow[t]{2}{*}{ stages } & \multicolumn{2}{|c|}{ Boys } & \multicolumn{2}{|c|}{ Girls } & \multirow{2}{*}{$\begin{array}{l}\text { Gender difference } \\
\text { Mean }\end{array}$} \\
\hline & Mean & $S D$ & Mean & $S D$ & \\
\hline $\mathrm{F}$ & 10.9 & 0.8 & 10.9 & 1.1 & 0 \\
\hline G & 12.8 & 0.9 & 12.2 & 1.1 & 0.6 \\
\hline $\mathrm{H}$ & 13.8 & 0.8 & 12.8 & 1.1 & 1.0 \\
\hline
\end{tabular}

statistically significant association with any M P3 stages in both the sexes. However, in the study by Chertkow and $\mathrm{Fatti}^{3}$ the canine stage $\mathrm{G}$ coincided with M P3-G stage significantly in Caucasian children while in B lack children no significant relationship was found, suggesting racial variations.

Hence according to our findings, canine calcification stages are not indicative of peak growth period (stage $G$ ), but only the beginning (stage $F$ ) in both the sexes and deceleration of growth (stage $\mathrm{H}$ ) only in boys. This study further confirms the influence of racial and gender factors on the lack of concordance among the results of previous studies. The predominant ethnic origin of the population, climate, nutrition, socioeconomic levels, and urbanization are indicated as the causative factors of these racial variations.

In this study, girls were found to mature earlier than boys by a mean age of 0.78 years. This is in agreement with the previous studies by Chapman, ${ }^{15} \mathrm{Fishman},{ }^{16} \mathrm{~K}$ railassiri et ${ }^{1}{ }^{1}$ and $U$ ysal et al. ${ }^{2}$ Similar to skeletal maturation, dental maturation occurred earlier in girls than in boys by almost a year and was also completed earlier in girls. Interestingly, the canine cal cification stage $F$ occurred at al most the same age in both the sexes, but as the root formation progressed the calcification stages occurred at a significantly later age in boys compared to girls with a progressive widening in the age difference. This suggests that a sexual dimorphism exists in mandibular canine tooth formation with an advanced trend in dental calcification in girls. This is in contrast to previous studies. Chertkow and $\mathrm{Fatti}^{3}$ reported 
Reliability of Permanent Mandibular Canine Calcification as an Indicator of Skeletal Maturity in Karnataka Population

that no significant sex differences were evident in the distribution of tooth mineralization stages for mandibular canine. Chertkow, ${ }^{4} \mathrm{~K}$ railassiri et $\mathrm{al}^{1}$ and Uysal et $\mathrm{al}^{2}$ have reported that the tooth mineralization relative to the skeletal maturation indicated an advanced trend in boys compared to girls. Conversely, B asaran et al ${ }^{17}$ stated that boys showed late dental development. This discrepancy between dental and chronological age could be attributed to racial variations between individuals in their rates of maturation since the previous studies were conducted on a different ethnic population.

\section{CONCLUSIONS}

The following conclusions were obtained:

- The stages of root formation of mandibular canine indicated only the onset of pubertal growth spurt for both the sexes and a period of decelerating growth velocity in boys.

- However the relationship was not consistent for all the stages of skel etal maturation and differed between boys and girls.

- A sexual dimorphism existed in canine tooth formation similar to skeletal maturation with an advanced trend in dental calcification in girls.

Hence the mandibular canine tooth calcification is not a very reliable skeletal maturity indicator in Karnataka population and is not recommended as a substitute to other conventional skeletal maturity indicators.

\section{ACKNOWLEDGMENTS}

Dr Dharma RM, Dr Prashanth CS, Dr A kshai Shetty KR, Departments of Orthodontics and Dentofacial Orthopedics, DA Pandu Memorial RV Dental College and Hospital, B engaluru, Karnataka, India.

\section{REFERENCES}

1. Krailassiri $\mathrm{S}$, Anuwongnukroh $\mathrm{N}$, Dechkunakorn $\mathrm{S}$. Relationships between dental calcification stages and skeletal maturity indicators in Thai individuals. Angle Orthod 2002; 72:155-65.

2. Uysal T, Sari Z, Ramoglu SI, B asciftci FA. Relationships between dental and skeletal maturity in T urkish subjects. A ngle Orthod 2004;74:657-63.

3. Chertkow S, Fatti P. R elationship betw een tooth mineralization and early radiographic evidence of ulnar sesamoid. Angle Orthod1979;49:282-88.

4. Chertkow S. Tooth mineralization as an indicator of pubertal growth spurt. A m J Orthod D entofacial Orthop 1980;77:79-91.

5. Sierra A. A ssessment of dental and skeletal maturity. Angle Orthod 1987;57:194-207.

6. Coutinho S, Buschang PH, M iranda F. M andibular canine calcification stages and skeletal maturity. A m J Orthod Dentofacial Orthop 1993;104:262-68.

7. Flores-M ir C, M auriciob FR, Orellanad M F, Majore PW. A ssociation between growth stunting with dental development and skel etal maturation stage. A ngle Orthod 2005;75:935-40.

8. Demirjian A, Buschang PH, Tanguay $R$, and Patterson DK. Interrelationships among measures of somatic, skel etal, dental and sexual maturity. A m J Orthod Dentofacial Orthop 1985;88:433-38.

9. Sahin Salam A M, Gazilerli U. The relationship between dental and skeletal maturity. J Orofac Orthop 2002;63:454-62.

10. L ewis A B. Comparison of dental and skel etal ages. A ngle Orthod 1991;71:87-92.

11. M appes M S, H arris EF , and B ehrents RG. R egional differences in tooth and bone development. A mJ Orthod Dentofacial Orthop 1992;101:145-51.

12. A bdel-K ader HM. The potential of digital dental radiography in recording the adductor sesamoid and the MP3 stages. Br J Orthod 1999;26:291-93.

13. Hagg U, Taranger J. M aturation indicators and the pubertal growth spurt. A m J Orthod Dentofacial Orthop 1982;82: 299-309.

14. Demirjian A, Goldstein H , Tanner J M . A new system of dental age assessment. Hum Biol 1973;45:211-27.

15. Chapman SM. Ossification of the adductor sesamoid and adolescent growth spurt. A ngle Orthod 1972;42:236-44.

16. Fishman LS. Radiographic evaluation of skeletal maturation. Angle Orthod 1982;52:88-111.

17. Ba_aran $G, O$ zer $T$, Hamamci N . Cervical vertebral and dental maturity in Turkish subjects. A m J Orthod Dentofacial Orthop 2007;131:447.e13-20. 